\title{
A novel long non-coding RNA TTN-AS1/microRNA-589-5p/FOXP1 positive feedback loop increases the proliferation, migration and invasion of pancreatic cancer cell lines
}

\author{
JING ZHAO $^{1}$, FANG WU ${ }^{2}$ and JUN YANG ${ }^{1}$ \\ ${ }^{1}$ Department of Gastroenterology, Liyang People's Hospital, Liyang, Jiangsu 213300; \\ ${ }^{2}$ Department of Gastroenterology, Wuxi People's Hospital, Wuxi, Jiangsu 214023, P.R. China
}

Received March 3, 2021; Accepted July 12, 2021

DOI: $10.3892 / \mathrm{ol} .2021 .13055$

\begin{abstract}
Numerous reports have found that long non-coding (lnc) RNAs were associated with pancreatic cancer (PC) initiation and development. The lncRNA titin antisense RNA 1 (TTN-AS1) was identified as a tumor promoter in certain types of cancer; however, its role and mechanism in PC remain unclear. The aim of the present study was to investigate the role of TTN-AS1 in PC and elucidate the underlying mechanism. Reverse transcription-quantitative PCR analysis was performed to examine the mRNA expression level of TTN-AS1, microRNA(miR)-589-5p and forkhead box protein 1 (FOXP1). Knockdown experiments were performed to examine the effect of TTN-AS1 on PC cell proliferation, migration and invasion. Luciferase reporter assays validated the binding of miR-589-5p to TTN-AS1 and FOXP1. Chromatin immunoprecipitation and luciferase reporter assays confirmed the binding ability of FOXP1 to the TTN-AS1 promoter. As a result, TTN-AS1 and FOXP1 were found to be upregulated in PC cell lines and tissues, while miR-589-5p was expressed at low levels. Knockdown experiments indicated the suppressive effect of TTN-AS1 knockdown on cell proliferation, migration and invasion in PC cell lines. Further mechanistic research uncovered that TTN-AS1 functioned as a molecular sponge for miR-589-5p and its mRNA expression level in PC tissues was inversely associated with that of miR-589-5p. Furthermore, miR-589-5p was confirmed to target FOXP1. Of note, it was discovered that FOXP1 transcriptionally activated TTN-AS1 mRNA expression level. Taken together, the findings of the present study demonstrated that the new
\end{abstract}

Correspondence to: Dr Jun Yang, Department of Gastroenterology, Liyang People's Hospital, 70 Jianshe West Road, Liyang, Jiangsu 213300, P.R. China

E-mail: jun_yang123@163.com

Key words: TTN-AS1, microRNA-589-5p, Forkhead box protein 1, pancreatic cancer
TTN-AS1/miR-589-5p/FOXP1 feedback loop may play an important role in PC.

\section{Introduction}

Pancreatic cancer (PC) is an aggressive type of cancer with an increasing incidence rate worldwide, with 216,000 new cancer cases worldwide every year, causing more than 200,000 deaths each year $(1,2)$. In recent years, PC has become the fourth main cause of cancer-associated mortality and its long-time survival rate is $\leq 5 \%$ due to its high degree of malignancy $(3,4)$. Furthermore, the intricate mechanisms underlying its pathological progression and the complicated regulatory mechanisms represent a considerable challenge in the early diagnosis of PC (5). Diagnosis and therapy have improved the survival times of patients, with the advances in imaging and clinical treatment methods (6); however, the clinical outcome of patients with PC remains unsatisfactory. Thus, it is crucial to further elucidate the possible underlying molecular mechanisms and identify new biomarkers for PC.

Long non-coding (lnc) RNAs are a type of ribose nucleotide chain and are $>200$ nucleotides in length (7). lncRNAs were previously considered to lack any biological functions, as they do not have protein-coding ability; however, it was discovered that lncRNAs can exert their biological functions via epigenetic regulation (8) at the transcriptional level, post-transcriptional level (9) or histone modification (10). Accumulating evidence has proved the particular significance of lncRNAs in the occurrence and progression of diverse diseases, particularly cancer, such as gastric cancer (11), colorectal cancer (12) and glioma (13). IncRNAs have been demonstrated to represent important elements of the competing endogenous (ce) RNA network by combining with microRNAs (miRNAs/miRs) to neutralize their inhibitory effects on target genes (14). In recent years, a number of lncRNAs have been confirmed to indirectly modulate gene expression by acting as ceRNAs in PC progression (15-17). The lncRNA titin antisense RNA 1 (TTN-AS1) has been found to play an oncogenic role in diverse types of cancer, such as gastric cancer (18), papillary thyroid cancer (19), cervical cancer (20) and hepatocellular carcinoma (21). Notably, TTN-AS1 has been shown to act as 
a ceRNA and plays a regulatory role by sponging different miRNAs $(22,23)$. For example, TTN-AS1 enhanced breast cancer cell invasion by regulating the miR-524-5p/ribonucleotide reductase regulatory subunit M2 axis (24). However, to the best of our knowledge, its significance in PC has not been investigated to date. The aim of the present study was to determine whether TTN-AS1 induced by forkhead box protein 1 (FOXP1) may function as an oncogene in $\mathrm{PC}$ via the miR-589-5p/FOXP1 axis, to identify a novel regulatory axis underlying $\mathrm{PC}$ progression.

\section{Materials and methods}

Tissue samples. A total of 78 paired specimens of PC and adjacent normal tissues were obtained from patients who had received surgical resection at Liyang People's Hospital (Liyang, China) between March 2017 and December 2019. Prior to surgery, none of the patients had received radiotherapy or chemotherapy. Patients that had been treated with chemotherapy or radiotherapy prior to surgery or lack of written informed consent were excluded from the study. The protocol of the present study was approved by the Ethics Committee of Liyang People's Hospital and written informed consent was provided by each patient. Immediately after collection, the tissues were frozen in liquid nitrogen and preserved at $-80^{\circ} \mathrm{C}$ until use.

Cell lines. The PC cell lines (BxPC-3, AsPC-1, CaPAN-2, PANC-1 and SW1990) were purchased from the American Type Culture Collection and the human pancreatic duct epithelial (HPDE) cell line was purchased from The Cell Bank of Type Culture Collection of The Chinese Academy of Sciences. All the cell lines were cultured in DMEM, supplemented with 10\% FBS (both from Gibco; Thermo Fisher Scientific, Inc.) and $1 \%$ penicillin-streptomycin, and incubated at $37^{\circ} \mathrm{C}$ in a humidified incubator with $5 \% \mathrm{CO}_{2}$.

Cell transfection. Short hairpin (sh) RNAs targeting TTN-AS1 (sh-TTN-AS1\#1 and-\#2) were designed to downregulate TTN-AS1 and sh-negative control (NC) served as the control. miR-589-5p mimics (5'-UUAUGGUUUGCCUGGGACUG AG-3') were purchased to increase miR-589-5p expression, with NC mimics (5'-UUCUCCGAACGUGUCACGUTT-3') as the control. To overexpress FOXP1, the pcDNA3.1/FOXP1 plasmid was generated and empty pcDNA3.1 was the control. All the aforementioned plasmids were purchased from Shanghai GenePharma Co., Ltd., and Lipofectamine ${ }^{\circledR} 2000$ (Invitrogen; Thermo Fisher Scientific, Inc.) was used to transfect $50 \mathrm{nM}$ sh-TTN-AS1\#1, $50 \mathrm{nM}$ sh-TTN-AS1\#2, $50 \mathrm{nM}$ sh-NC, $50 \mathrm{nM}$ miR-589 mimics, $50 \mathrm{nM}$ NC mimics, $4.0 \mu \mathrm{g}$ pcDNA3.1/FOXP1 and 4.0 $\mu \mathrm{g}$ pcDNA3.1 into the BxPC-3 and AsPC-1 cell lines at room temperature for $\sim 30 \mathrm{~min}$. Reverse transcription-quantitative (RT-q) PCR analysis was used to confirm transfection efficiency. Subsequent experiments were performed $48 \mathrm{~h}$ post-transfection.

RT-qPCR analysis. Total RNA was extracted from the PC tissues or cells using TRIzol ${ }^{\circledR}$ (Invitrogen; Thermo Fisher Scientific, Inc.) according to the manufacturer's protocol. Subsequently, total RNA was reverse transcribed into cDNA using the ReverTra Ace qPCR RT kit (Takara Biotechnology Co., Ltd.), according to the manufacturer's protocol. The SYBR Green real-time PCR Master Mix (Takara Biotechnology Co., Ltd.) was used for qPCR on an ABI 7500 real-time PCR system (Applied Biosystems; Thermo Fisher Scientific, Inc.). The thermocycling conditions were as follows: Pre-denaturation at $95^{\circ} \mathrm{C}$ for $1 \mathrm{~min}$, followed by 40 cycles of $95^{\circ} \mathrm{C}$ for $15 \mathrm{sec}$, $60^{\circ} \mathrm{C}$ for $30 \mathrm{sec}$ and $72^{\circ} \mathrm{C}$ for $30 \mathrm{sec}$. GAPDH (for lncRNA and mRNA) or U6 (for miRNA) served as the internal references. Finally, the $2^{-\Delta \Delta C q}$ method (25) was used to calculate and analyze relative target gene expression. The primer sequences were designed as follows: TTN-AS1 forward, 5'-CGATAC CATTGAACACGCTGC-3' and reverse, 5'-GGTTGAGGG TCCCAGTG-3'; miR-589-5p forward, 5'-CGCCTTGAATCG GTG-3' and reverse, 5'-GTGCAGGGTCCGAGGT-3'; FOXP1 forward, 5'-AGGACTTGCACAAGCAGAAC-3' and reverse, 5'-GTTGGCGTACACGGGCGGCT-3'; GAPDH forward, 5'-AGCCACATCGCTCAGACAC-3' and reverse, 5'-GCC CAATACGACCAAATCC-3'; and U6 forward, 5'-GCTTCG GCAGCACATATACTAAAAT-3' and reverse, 5'-CGCTTC ACGAATTTGCGTGTCAT-3'.

Cell Counting Kit (CCK)-8 assay. To measure cell viability, the BxPC-3 and AsPC-1 cell lines were plated into 96-well plates $\left(2 \times 10^{3}\right.$ cells/well), and incubated for $0,24,48$ and $72 \mathrm{~h}$. Following which, $10 \mu \mathrm{l} \mathrm{CCK-8} \mathrm{solution} \mathrm{(Dojindo} \mathrm{Molecular}$ Technologies, Inc.) was added per well and the samples were incubation for an additional $2 \mathrm{~h}$ until the cells adhered. Finally, the absorbance at $450 \mathrm{~nm}$ was detected.

Colony formation assay. A total of 1,500 BxPC-3 and AsPC-1 cells per well were seeded into 6 -well plates and the transfected cells were cultured for 2 weeks under normal culture conditions. Then, the cells were fixed in $4 \%$ paraformaldehyde for $10 \mathrm{~min}$ and stained using $0.5 \%$ crystal violet solution for $10 \mathrm{~min}$ at room temperature, respectively. After washing three times with PBS, images of the cell colonies were captured and counted under a light microscope (magnification, x20).

Transwell assay. A 24-well Transwell chamber (Corning, Inc.) containing a polycarbonate membrane filter $(8-\mu \mathrm{m}$ pore size) was used for the Transwell assays. To investigate invasion, the chamber was precoated with $100 \mu \mathrm{g}$ Matrigel for $1 \mathrm{~h}$ at room temperature, whereas this step was omitted for the migration assay. Briefly, $5 \times 10^{4}$ cells in serum-free medium were plated in the top chamber and the bottom chamber was filled with medium $(500 \mu 1)$, supplemented with 10\% FBS. After incubating for $24 \mathrm{~h}$ at $37^{\circ} \mathrm{C}$, the cells remaining in the upper side of the filter were removed using cotton-tipped swabs. The cells that had migrated or invaded into the lower side of the filter were fixed with $4 \%$ methanol for $20 \mathrm{~min}$ and stained with $0.1 \%$ crystal violet for $20 \mathrm{~min}$, both at room temperature, and finally counted under an light microscope (magnification, x200).

Bioinformatic analysis. The StarBase 2.0 database (http://starbase.sysu.edu.cn/) was used to predict the binding sites between miR-589-5p and TTN-AS1 or FOXP1. Santa Cruz Genome Browser (http://genome.ucsc.edu) was used to predict the potential transcription factor of TTN-AS1. 
Luciferase reporter assay. The corresponding full-length sequence of TTN-AS1 or FOXP1 3'-untranslated region (UTR) with wild-type (WT) or mutated (Mut) miR-589-5p binding sites was ligated into the pmirGLO vector (Promega Corporation) to form pmirGLO-TTN-AS1-WT/Mut or pmirGLO-FOXP1-WT/Mut reporter vectors. Then, the constructed reporter vectors were co-transfected with miR-589-5p mimics or NC mimics into the BxPC-3 and AsPC-1 cells, using Lipofectamine ${ }^{\circledR} 2000$ (Invitrogen; Thermo Fisher Scientific, Inc.). After 48 h, the relative luciferase activities were measured using a Dual-Luciferase Reporter Assay System (Promega Corporation). Firefly luciferase activity was normalized to Renilla luciferase activity.

The fragments of the TTN-AS1 promoter containing the FOXP1-binding site (WT or Mut) were ligated into the pGL3-basic vector (Promega Corporation). Subsequently, the recombinant construct was co-transfected with pcDNA3.1/FOXP1 plasmids into the BxPC-3 and AsPC-1 cell lines, using Lipofectamine 2000 (Invitrogen; Thermo Fisher Scientific, Inc.). After $48 \mathrm{~h}$, the relative luciferase activity was examined using the Dual Luciferase Reporter Gene Assay kit (BioTek Instruments, Inc.) to analyze firefly and Renilla luciferase activities.

Chromatin immunoprecipitation (ChIP) assay. The BxPC-3 and AsPC-1 cell lines were collected and fixed with $1 \%$ formaldehyde for $10 \mathrm{~min}$ at $37^{\circ} \mathrm{C}$ for cross-linking DNA and protein. Next, ultrasonication was used to generate DNA fragments (200-500 bp). Then, the cell lysates, with the DNA fragments, were immunoprecipitated with anti-FOXP1 $(1: 1,000$; cat. no. ab93807) or anti-IgG (1:10,000; cat. no. ab172730) (both from Abcam). Subsequently, magnetic beads were used to capture the precipitated DNA fragments and the precipitated DNA was quantified using RT-qPCR.

Western blot analysis. Total protein was isolated from the PC cells using RIPA lysis buffer (Thermo Fisher Scientific, Inc.). Protein concentration was detected using a BCA assay kit (Sangon Biotech Co., Ltd.). The total protein $(20 \mu \mathrm{g})$ was separated with $10 \%$ SDS-PAGE, then transferred to a PVDF membrane. After blocking with 5\% skimmed milk for $2 \mathrm{~h}$, the membrane was incubated with the primary antibodies against E-cadherin (cat. no. ab1416; 1:1,000), N-cadherin (cat. no. ab18203; 1: 1,000) and GAPDH (cat. no. ab9485; $1: 1,000)$ overnight at $4^{\circ} \mathrm{C}$. Subsequently, the membrane was incubated with goat anti-rabbit IgG H\&L (HRP) secondary antibody (1:1,000; cat. no. ab205718; Abcam) and the bands were evaluated using an enhanced chemiluminescence kit (Pierce; Thermo Fisher Scientific, Inc.).

Statistical analysis. Data from independent triplicate experiments were analyzed via SPSS 20.0 (IBM Corp.) and are shown as the mean $\pm \mathrm{SD}$. The comparison between two groups was conducted using paired or unpaired Student's t-test and between multiple groups using one-way ANOVA followed by Tukey's post hoc test. The correlation between mRNA expression levels was analyzed using Pearson's correlation analysis. The $\chi^{2}$ test was used to assess the associations between TTN-AS1 expression and the clinicopathological characteristics. $\mathrm{P}<0.05$ was considered to indicate a statistically significant difference.
Table I. Association between TTN-AS1 and the clinicopathological characteristics in patients with pancreatic cancer.

\begin{tabular}{llll}
\hline & \multicolumn{2}{c}{ TTN-AS1 } \\
& expression level & \\
\cline { 2 - 3 } Characteristic & High & Low & P-value \\
\hline Age, years & & & \\
$\geq 60$ & 25 & 21 & 0.621 \\
$<60$ & 20 & 12 & \\
Sex & & & \\
Male & 23 & 17 & 0.932 \\
Female & 22 & 16 & \\
TNM stage & & & \\
I-II & 14 & 20 & 0.021 \\
III-IV & 31 & 13 & \\
Lymph node metastasis & & & \\
Negative & 13 & 27 & $<0.001$ \\
Positive & 32 & 6 & \\
\hline
\end{tabular}

TTN-AS1, titin antisense RNA 1.

\section{Results}

TTN-AS1 silencing inhibits PC cell proliferation. To examine the function of TTN-AS1 in PC, its mRNA expression levels were first detected using RT-qPCR. As shown in Fig. 1A, TTN-AS1 was found to be significantly increased in PC tissues. Furthermore, clinical data demonstrated that TTN-AS1 expression was associated with TNM stage and lymph node metastasis, while there was no significant association between TTN-AS1 mRNA expression level and age or sex (Table I). Then, TTN-AS1 mRNA expression level was analyzed in the $\mathrm{PC}$ and HPDE cell lines, the latter was used as the NC. The results of RT-qPCR indicated that the PC cell lines exhibited higher TTN-AS1 mRNA expression levels compared with that in the HPDE cell line (Fig. 1B). Furthermore, the BxPC-3 and AsPC-1 cell lines exhibited the highest TTN-AS1 mRNA expression level; thus, these two cell lines were selected for further experiments. Subsequently, TTN-AS1 expression was knocked down using shRNA in the BxPC-3 and AsPC-1 cell lines, and the transfection efficiency was confirmed using RT-qPCR (Fig. 1C). CCK-8 assays revealed that knock down of TTN-AS1 significantly suppressed the viability of both the BxPC-3 and AsPC-1 cell lines (Fig. 1D). In addition, colony formation assays further verified the inhibitory effect of TTN-AS1 knockdown on BxPC-3 and AsPC-1 cell proliferation (Fig. 1E). Lastly, Transwell and Matrigel assays demonstrated that TTN-AS1 knockdown reduced the migration and invasion abilities of the BxPC-3 and AsPC-1 cell lines (Fig. 1F and G, respectively). The aforementioned findings indicated that TTN-AS1 may act as an oncogene in PC.

TTN-AS1 sponges miR-589-5p in PC. A number of studies have found that lncRNAs play key roles in cancer by combining with miRNAs (26-28); thus, it was investigated whether potential 
A

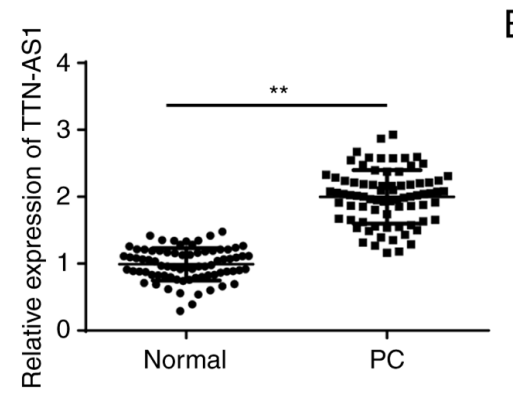

B

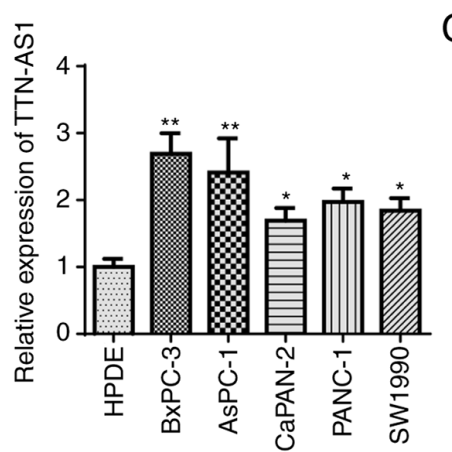

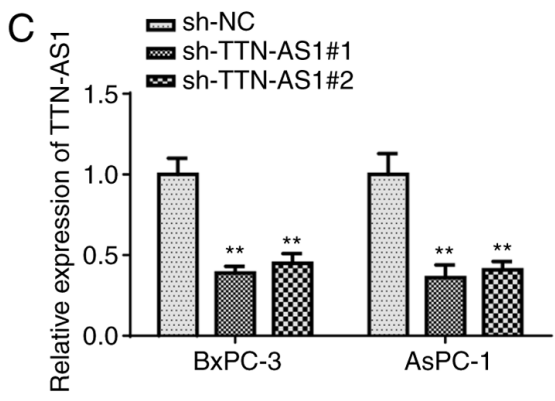

AsPC-1

D

BxPC-3

- sh-NC

- sh-TTN-AS1\#1
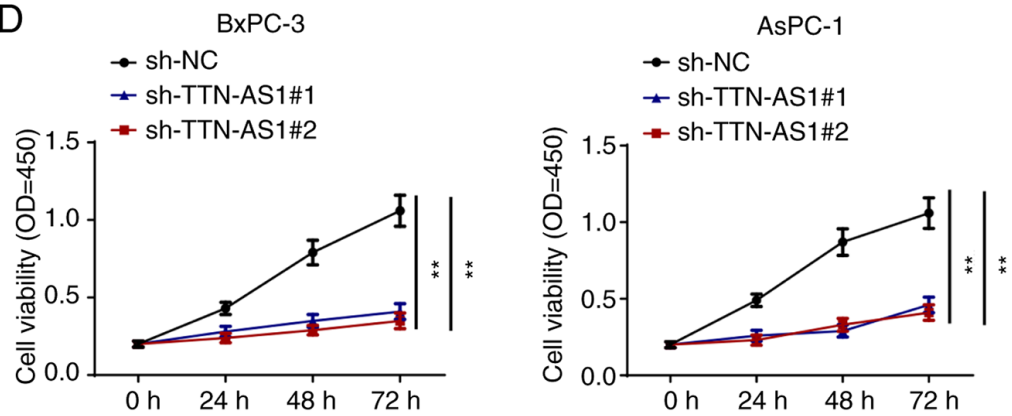

E
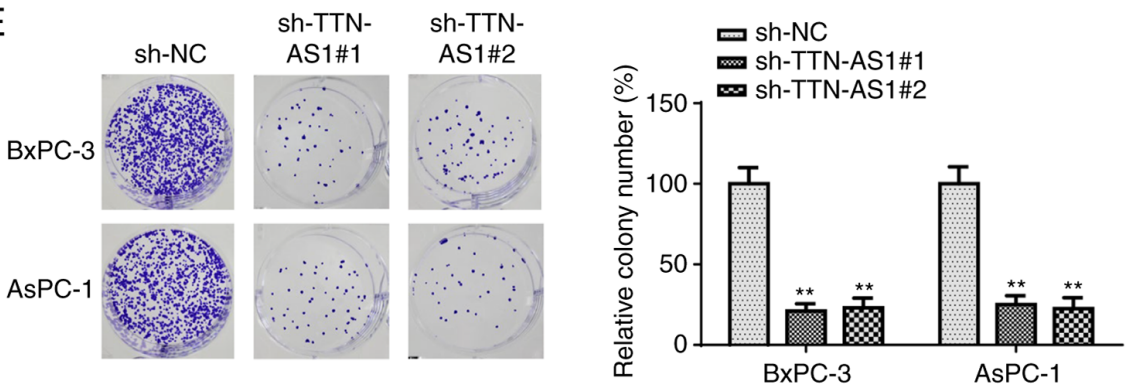

F
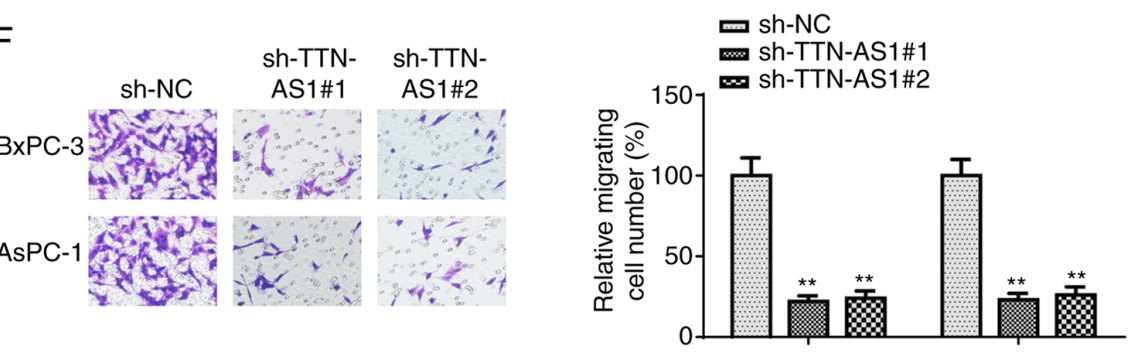

G

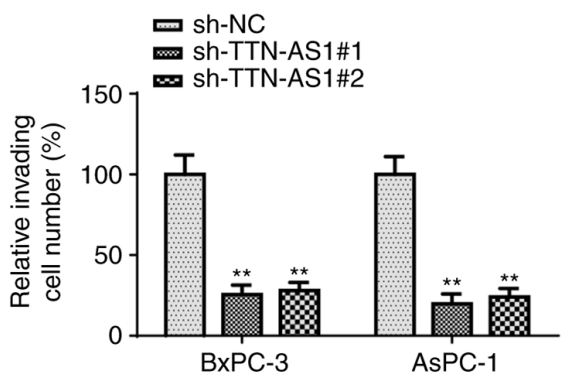

Figure 1. Expression level and biological function of TTN-AS1 in PC tissues and cell lines. The mRNA expression level of TTN-AS1 in (A) PC tissues and (B) cell lines. Adjacent normal tissues and the HPDE cell line were used as the negative control, respectively. (C) TTN-AS1 mRNA expression level was detected using reverse transcription-quantitative PCR in the BxPC-3 and AsPC-1 cell lines transfected with sh-TTN-AS1\#1 or \#2 and sh-NC was used as the negative control. (D) Cell Counting Kit-8 and (E) colony formation assays were performed to investigate the effect of TTN-AS1 knockdown on BxPC-3 and AsPC-1 cell viability and proliferation, respectively. Transwell assays were performed to analyze BxPC-3 and AsPC-1 cell (F) migration and (G) invasion following knockdown of TTN-AS1. ${ }^{*}<0.05,{ }^{* *} \mathrm{P}<0.01$, sh-TTN-AS1\#1 or sh-TTN-AS1\#1 vs. sh-NC. PC, pancreatic cancer; sh, short hairpin; NC, negative control; TTN-AS1, titin antisense RNA 1. 

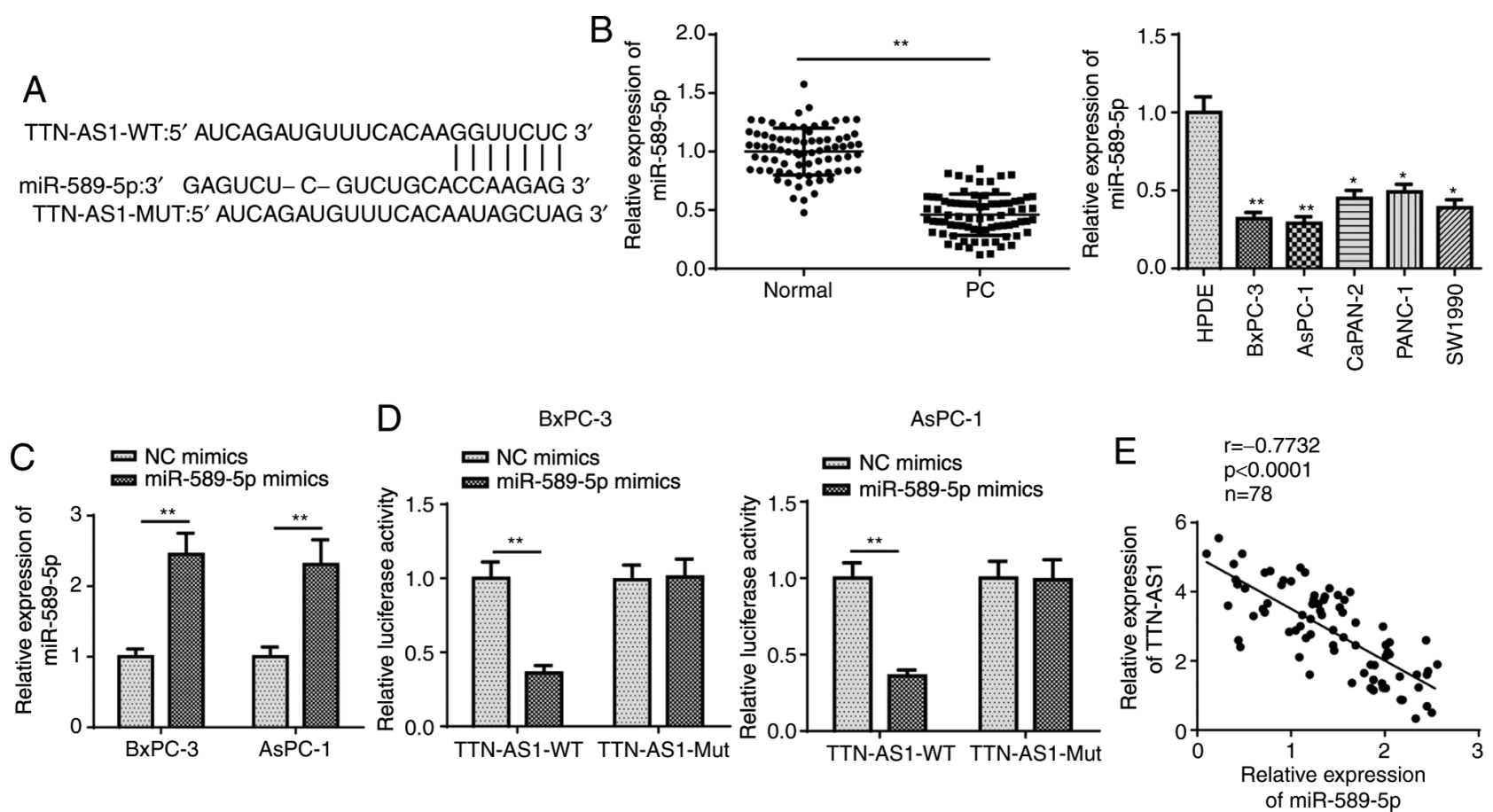

Figure 2. TTN-AS1 interacts with miR-589-5p. (A) The binding sequences between TTN-AS1 and miR-589-5p were obtained using StarBase database. (B) miR-589-5p expression level in PC tissues and cell lines was evaluated using RT-qPCR analysis. (C) RT-qPCR analysis was used to confirm the transfection efficiency of miR-589-5p mimics. (D) The luciferase activity of TTN-AS1-WT/Mut in miR-589-5p-overexpressed BxPC-3 and AsPC-1 cell lines was demonstrated using a luciferase reporter assay. (E) The correlation between TTN-AS1 and miR-589-5p mRNA expression level was analyzed using Pearson correlation analysis. ${ }^{*} \mathrm{P}<0.05,{ }^{* *} \mathrm{P}<0.01$. miR, microRNA; NC, negative control; WT, wild-type; Mut, mutant; PC, pancreatic cancer; TTN-AS1, titin antisense RNA 1; RTqPCR, reverse transcription-quantitative PCR.

miRNAs could interact with TTN-AS1. To predict potential miRNAs, StarBase database (http://starbase.sysu.edu.cn/) was used. As a result, TTN-AS1 was found to potentially combine with miR-589-5p under strict screening conditions (Pan-Cancer, 10 cancer types), and the binding sequence of TTN-AS1 on miR-589-5p is illustrated in Fig. 2A. Subsequently, miR-589-5p mRNA expression level was determined and found to be low in PC tissues and cell lines (Fig. 2B). In further experiments, miR-589-5p mRNA expression level was increased following transfection with miR-589-5p mimics (Fig. 2C). Subsequently, the plasmids containing the WT (TTN-AS1-WT) and Mut (TTN-AS1-Mut) miR-589-5p binding site were generated and ligated into dual-luciferase reporter vectors for luciferase activity assay. The results revealed that the luciferase activity of TTN-AS1-WT was inhibited by miR-589-5p overexpression, but that of TTN-AS1-Mut was unaffected (Fig. 2D), suggesting the direct binding of TTN-AS1 to miR-589-5p. Furthermore, Pearson's correlation analysis demonstrated the inverse association between TTN-AS1 and miR-589-5p expression levels in the PC tissues (Fig. 2E). Collectively, these findings indicated that TTN-AS1 directly interacted with miR-589-5p in PC.

FOXP1 is the downstream target of miR-589-5p in PC. To further verify the ceRNA hypothesis, the downstream target genes of miR-589-5p were investigated. Using StarBase, 10 potential candidate targets were identified (Fig. 3A) and the mRNA expression level of these genes in the miR-589-5p mimics-transfected cells was examined using RT-qPCR. The results revealed that FOXP1 expression was lower compared with that in the other 9 genes when miR-589-5p was overexpressed (Fig. 3B). Thus, FOXP1 was selected for subsequent analyses. As shown in Fig. 3C, PC tissues expressed higher expression levels of FOXP1 compared with that in adjacent normal tissues. RT-qPCR and western blot analyses also indicated that the mRNA and protein expression level of FOXP1 was upregulated in the PC cell lines compared with that in the HPDE cell lines (Fig. 3D and E, respectively). Furthermore, it was demonstrated that the luciferase activity of FOXP1-WT, but not that of FOXP1-Mut, was significantly reduced in the miR-589-5p mimics-transfected cells (Fig. 3F). In addition, FOXP1 expression in the PC tissues was found to be negatively correlated with miR-589-5p and positively correlated with TTN-AS1 mRNA expression levels using Pearson's correlation analysis (Fig. 3G). Taken together, these findings indicated that miR-589-5p directly targeted FOXP1 in PC.

TTN-AS1 is transcriptionally activated by FOXP1. According to previous reports, FOXP1 may act as a transcription factor and promote the transcription of lncRNAs $(29,30)$. However, to the best of our knowledge, whether FOXP1 can transcriptionally activate the expression of TTN-AS1 has not been investigated to date. Using the University of California, Santa Cruz Genome Browser (http://genome.ucsc.edu/), FOXP1 was found to act as a potential transcription factor by binding to the TTN-AS1 promoter, and its DNA motif was obtained from the JASPAR database (http://jaspar.genereg.net) (Fig. 4A). Then, the pcDNA3.1/FOXP1 plasmid was transfected into the BxPC-3 and AsPC-1 cell lines to increase FOXP1 expression (Fig. 4B and C). Subsequently, TTN-AS1 mRNA expression level was found to be significantly increased by pcDNA3.1/FOXP1 transfection (Fig. 4D). ChIP assay revealed the direct interaction between 
B

BxPC-3

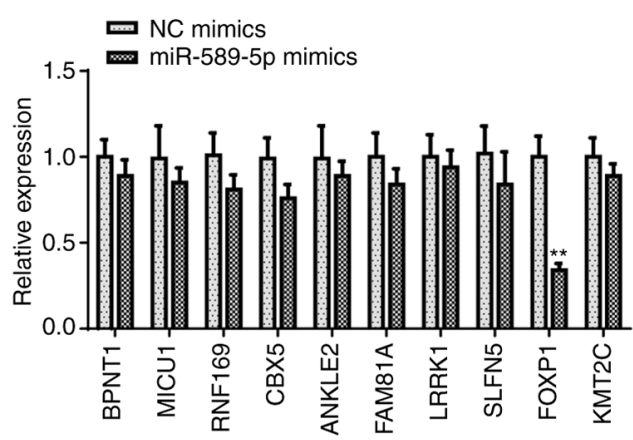

AsPC-1

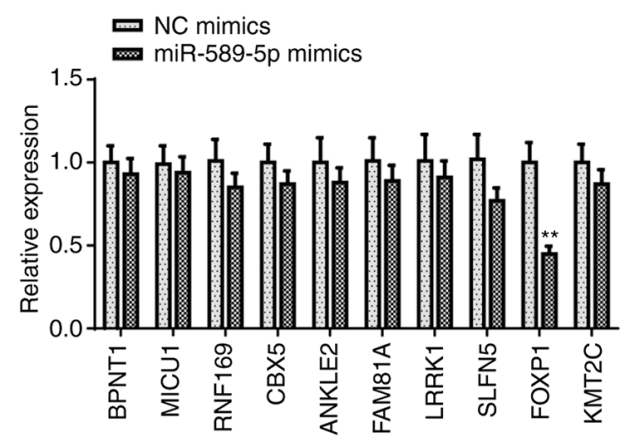

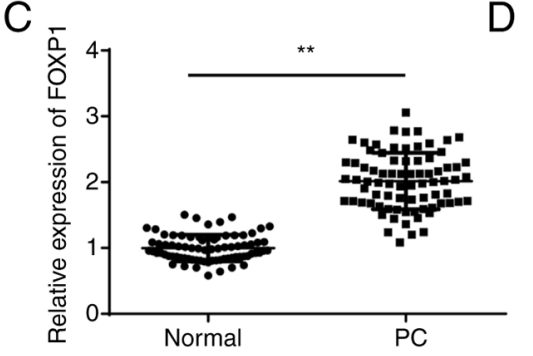

$\mathrm{F}$ FOXP1-WT: 5' CCCUCAGCAGCUCCAGGUUCUC $3^{\prime}$ |||||| miR-589-5p: 3' GAGUCUCGUC-UGCACCAAGAG 3 FOXP1-Mut: $5^{\prime}$ CCCUCAGCAGCUCCAUUAAGCG 3

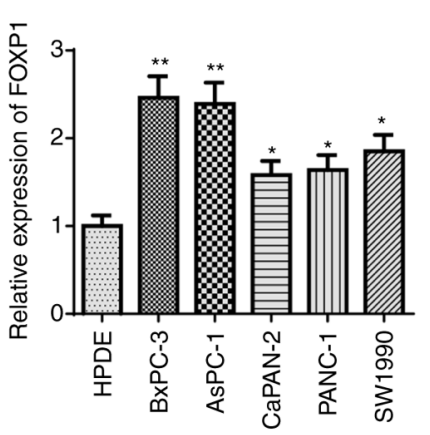

BxPC-3

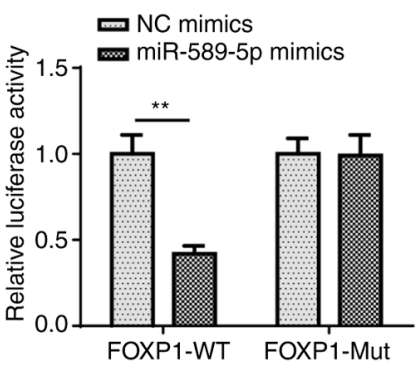

E

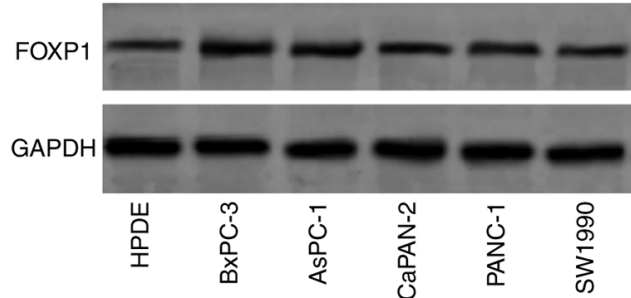

AsPC-1

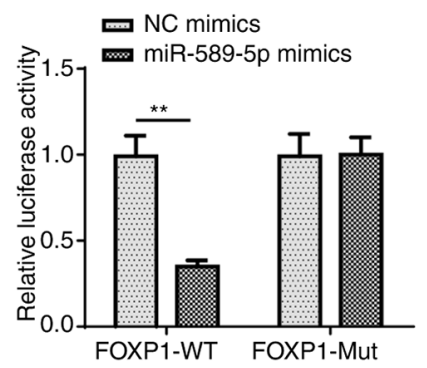

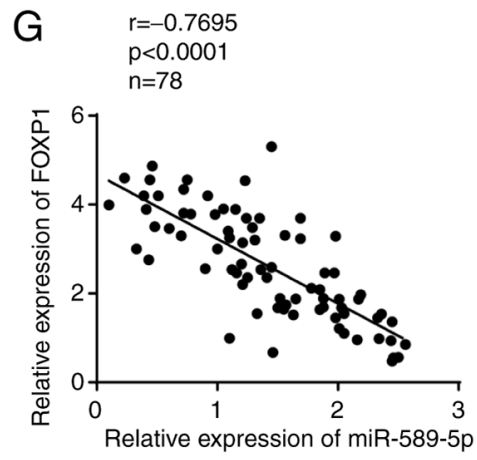

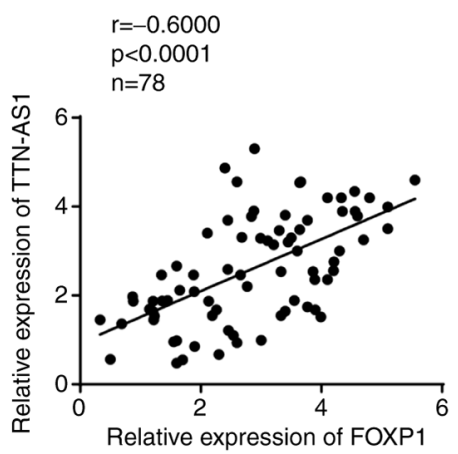

Figure 3. FOXP1 is targeted by miR-589-5p. (A) The potential target genes for miR-589-5p were predicted using StarBase. (B) The mRNA expression level of the predicted targets in the BxPC-3 and AsPC-1 cell lines transfected with miR-589-5p mimics. (C) Reverse transcription-quantitative PCR analysis of FOXP1 expression in PC and adjacent normal tissues. The (D) mRNA and (E) protein expression levels of FOXP1 were measured in the PC cell lines and the human pancreatic duct epithelial cell line. (F) The interaction between miR-589-5p and FOXP1 was confirmed using a luciferase reporter assay. (G) Pearson correlation analysis revealed the correlation between FOXP1 and miR-589-5p, and with TTN-AS1. ${ }^{*} \mathrm{P}<0.05,{ }^{* *} \mathrm{P}<0.01$, $\mathrm{PC}$ or experiment groups vs. control group. miR, microRNA; NC, negative control; PC, pancreatic cancer; TTN-AS1, titin antisense RNA 1; WT, wild-type; Mut, mutant; FOXP1, forkhead box protein 1.

FOXP1 and the TTN-AS1 promoter (Fig. 4E). Subsequently, the WT and Mut binding sites between FOXP1 and TTN-AS1 promoter were obtained, and a luciferase reporter assay revealed that FOXP1 overexpression increased the luciferase activity of the WT TTN-AS1 promoter reporter construct, while no notable changes were observed with the Mut TTN-AS1 promoter reporter (Fig. 4F). All these data indicated that FOXP1 directly binds to the TTN-AS1 promoter.

TTN-AS1 is associated with PC cell line migration and invasion by upregulating FOXP1. To verify whether TTN-AS1 promoted PC progression via FOXP1, rescue experiments were 


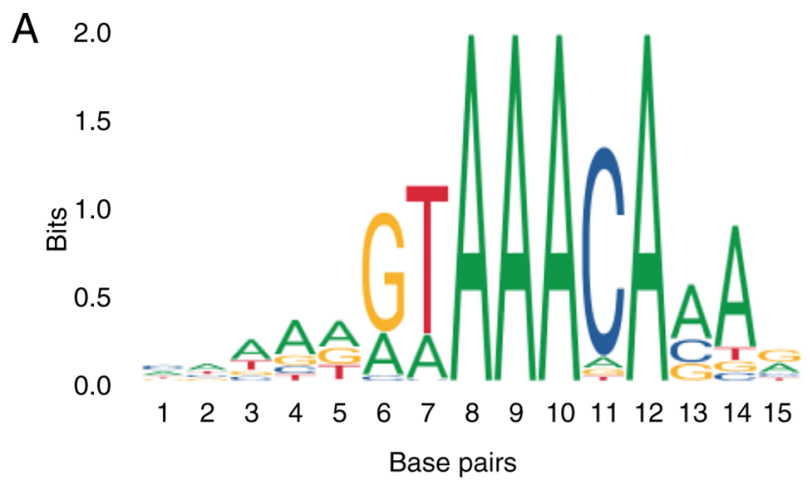

A 2.0
D $\quad$ pcDNA3.1

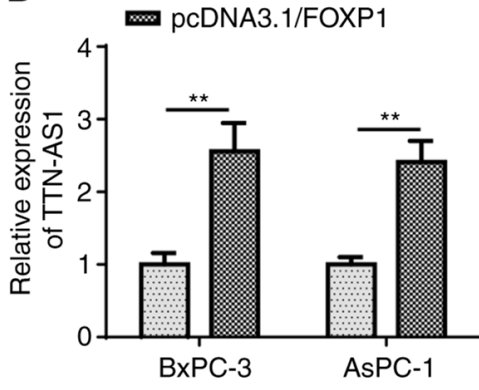

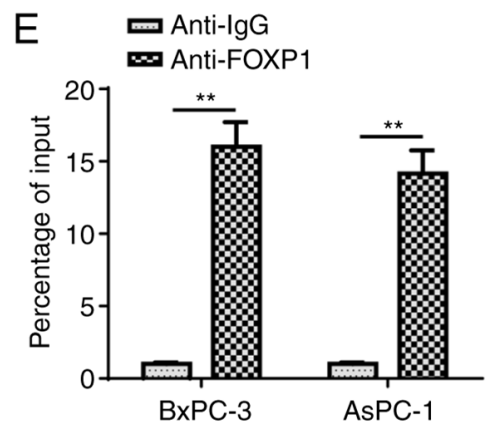

$\mathrm{F}$

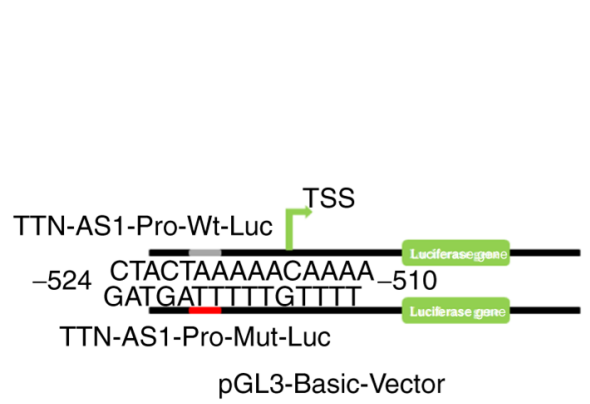

BxPC-3

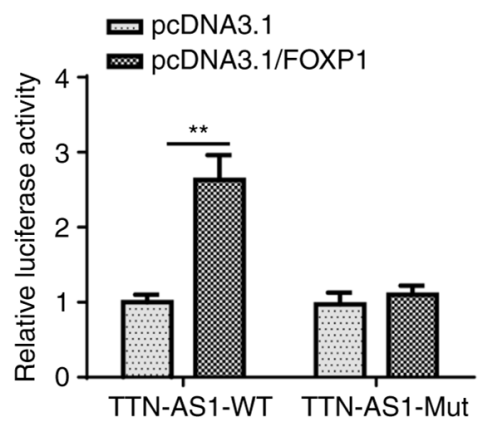

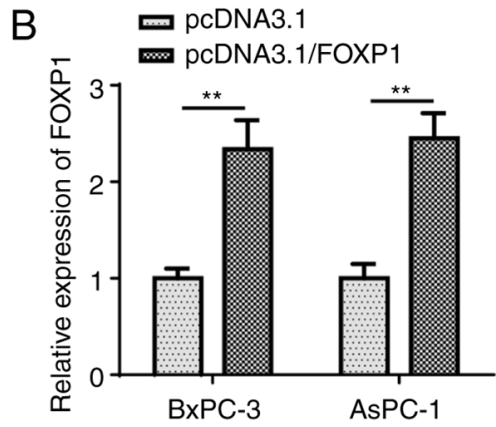

Figure 4. TTN-AS1 is induced by FOXP1. (A) The DNA motif of FOXP1. FOXP1 (B) mRNA and (C) protein expression level in pcDNA3.1/FOXP1-transfected cells was determined using RT-qPCR and western blot analysis, respectively. (D) RT-qPCR analysis was used for determining TTN-AS1 mRNA expression level in the BxPC-3 and AsPC-1 cell lines following pcDNA3.1/FOXP1 transfection. (E) Chromatin immunoprecipitation assay was utilized to verify the binding between FOXP1 and TTN-AS1 promoter. (F) The binding site (WT/Mut) between FOXP1 and TTN-AS1 promoter was formed and luciferase activity of TTN-AS1 promoter-WT/Mut was evaluated using a luciferase reporter assay with FOXP1 overexpression. ${ }^{* *}$ P<0.01. WT, wild-type; Mut, mutant; FOXP1, forkhead box protein 1; TTN-AS1, titin antisense RNA 1.

performed. Based on the results of the CCK-8 assay, FOXP1 upregulation counteracted the inhibitory effect of TTN-AS1 knockdown in PC cell viability (Fig. 5A). The results of the colony formation assay suggested that the suppressed proliferative ability in TTN-AS1 knockdown cells was restored by increasing the expression level of FOXP1 (Fig. 5B). Furthermore, TTN-AS1 knockdown inhibited the migration and invasion of the BxPC-3 and AsPC-1 cells, while the overexpression of FOXP1 recovered this effect (Fig. 5C and D). In addition, the results of western blot analysis demonstrated that TTN-AS1 knockdown notably increased and decreased E-cadherin and $\mathrm{N}$-cadherin protein expression levels, while FOXP1 overexpression partially reversed this effect (Fig. 5E). In conclusion, TTN-AS1 upregulated FOXP1 to facilitate PC cell line migration and invasion.

\section{Discussion}

$\mathrm{PC}$ is an aggressive malignancy, and its development and progression are intricate processes involving the accumulation of epigenetic or genetic variations. Further elucidating the mechanisms underlying PC tumorigenesis is crucial for decreasing the $\mathrm{PC}$-associated mortality rate $(31,32)$. Extensive evidence has indicated the important role of lncRNAs in cancer progression (33-35). Thus, the regulatory mechanisms underlying the roles of lncRNAs in mediating malignant or abnormal biological behavior must be further investigated. Various lncRNAs have been associated with PC (36,37); however, to the best of our knowledge, the detailed role and mechanism of TTN-AS1 in PC has not been elucidated. Previously, TTN-AS1 was confirmed to facilitate cervical 

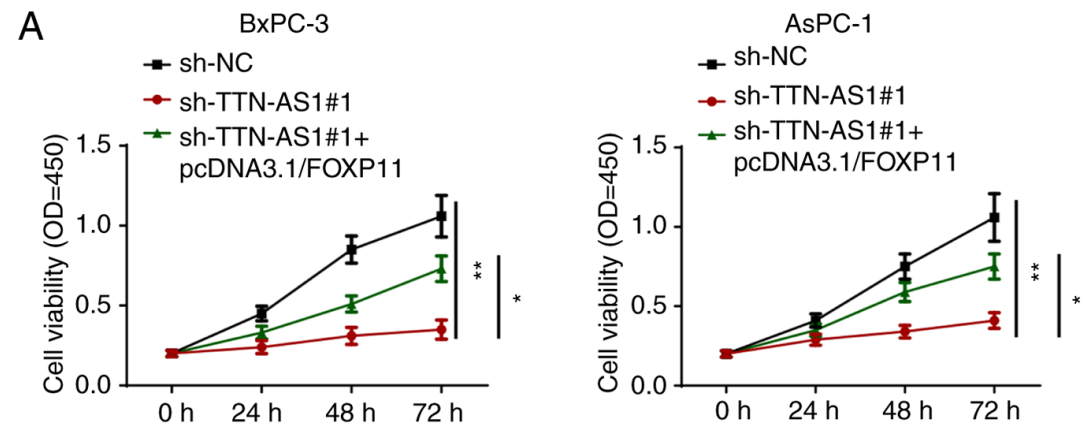

B

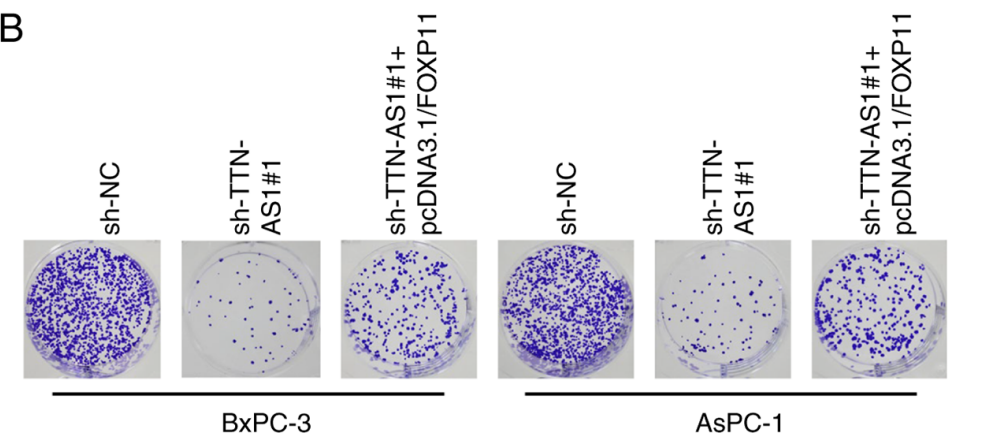

C
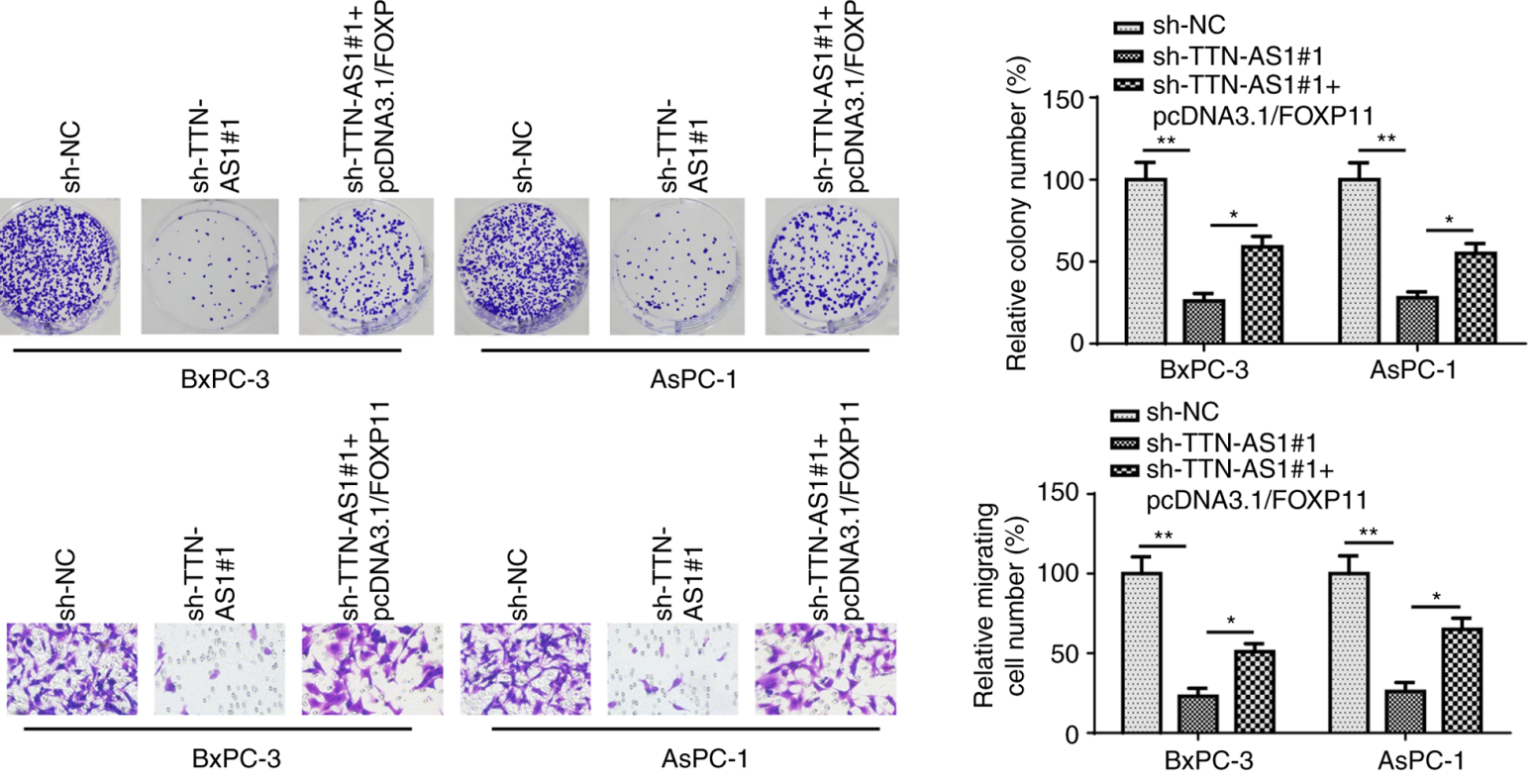

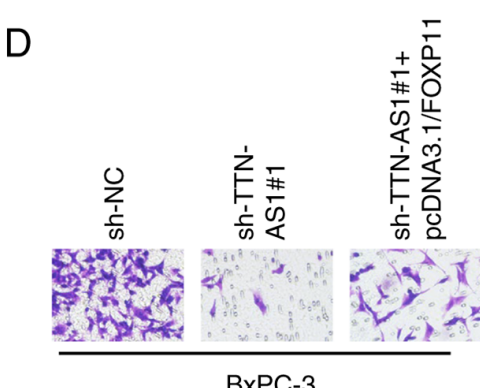

BxPC-3

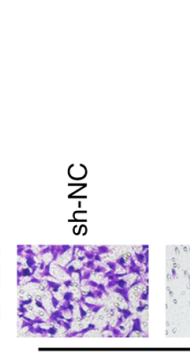

क. त्र

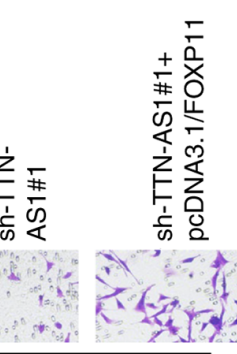

AsPC-1
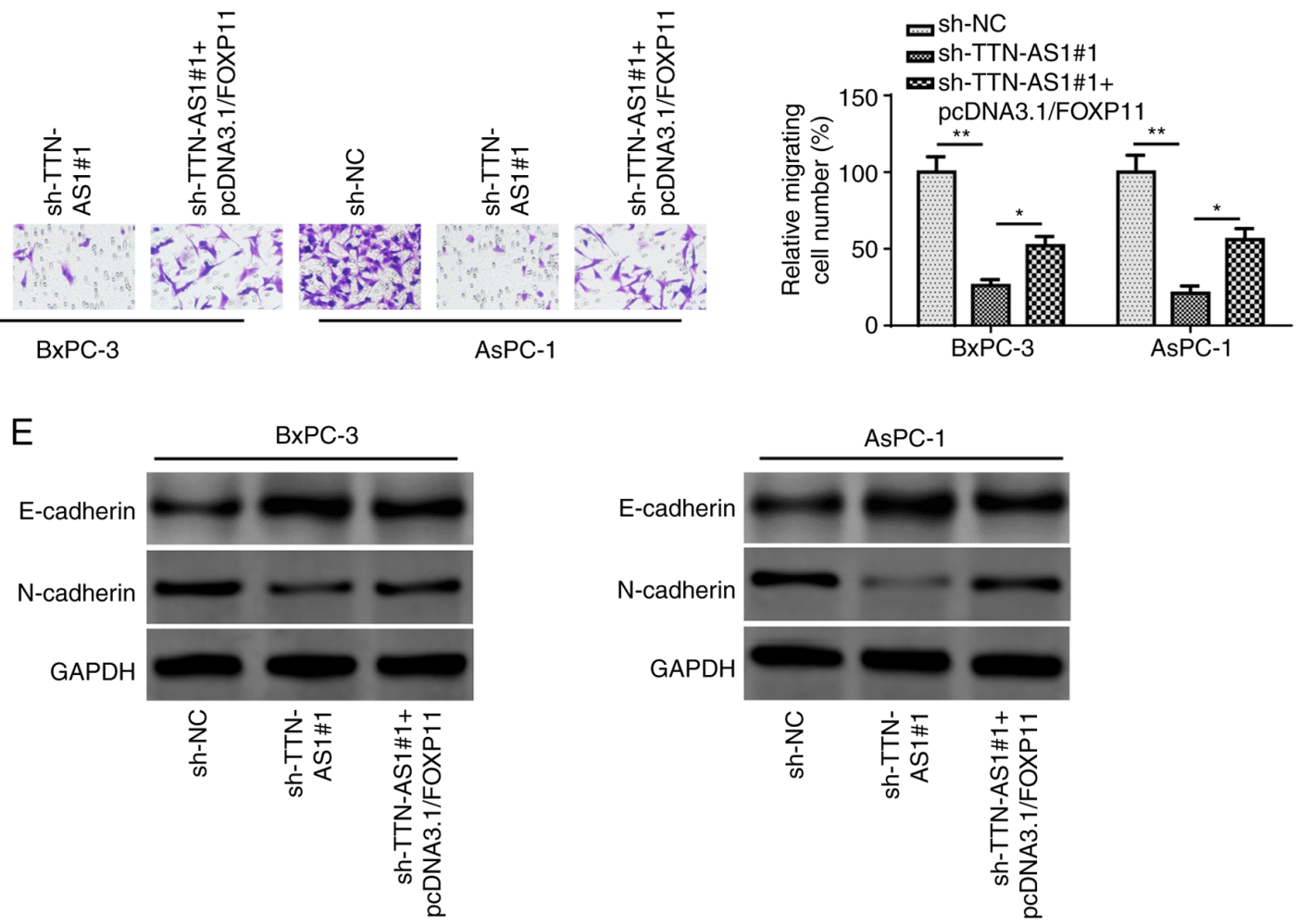

Figure 5. FOXP1 rescues the effect of TTN-AS1 knockdown on PC cellular migration and invasion. The cells were divided into the sh-NC, sh-TTN-AS1\#1 and sh-TTN-AS1\#1+pcDNA3.1/FOXP1 groups. (A) Cell Counting Kit-8 and (B) colony formation assays were performed to evaluate cell viability and proliferation in each group, respectively. The (C) migration and (D) invasion of the BxPC-3 and AsPC-1 cell lines in each group were analyzed using Transwell assays. (E) E-cadherin and $\mathrm{N}$-cadherin protein expression levels were detected using western blot analysis. ${ }^{*} \mathrm{P}<0.05$, $^{* *} \mathrm{P}<0.01$. FOXP1, forkhead box protein 1 ; NC, negative control; sh, short hairpin; TTN-AS1, titin antisense RNA 1. 
cancer growth and metastasis via the miR-573/E2F3 axis (20). Furthermore, TTN-AS1 was found to act as a tumor promoter in papillary thyroid cancer by enhancing cell proliferation and migration via the miR-153-3p/ZNRF2 axis (19). In addition, TTN-AS1 was also reported to upregulate KLF12 and accelerate gastric cancer progression by sponging miR-376b-3p (18). In the present study, the IncRNA TTN-AS1 was found to be upregulated in PC tissues and cell lines, whereas TTN-AS1 knockdown significantly reduced the proliferation, migration and invasion abilities of the PC cell lines. Collectively, these findings support the oncogenic properties of TTN-AS1 in PC.

It was previously revealed that the majority of the genome is transcribed as non-coding RNAs, including lncRNAs and miRNAs (38). miRNAs, which are 21-24 nucleotides in length, are single-stranded RNAs that can target mRNA 3'-UTRs to trigger translation inhibition or degradation (39). The functional role of miRNAs in cancer has also been widely reported. For example, miRNA-129-5p was shown to inhibit lymph node metastasis and lymphangiogenesis in nasopharyngeal carcinoma cell lines (40). miR-127-3p and miR-376a-3p exerted suppressive effects on cell proliferation in osteosarcoma cell lines (41). Of note, multiple miRNAs were found to be decreased and play biologically significant roles in PC, such as miR-15a (42), miR-3924 (15) and miR-30a-3p (43). Interacting with miRNAs to indirectly modulate target gene expression is a common mechanism of action of IncRNAs (44). miR-589-5p was previously demonstrated to serve as a tumor inhibitor in endometrial carcinoma cell lines (45), and was associated with the ceRNA mechanism in hepatocellular carcinoma cell lines (46). In the present study, miR-589-5p was found to be sponged by TTN-AS1 in PC cell lines, and there was an inverse correlation between TTN-AS1 and miR-589-5p mRNA expression level.

FOXP1 has been associated with B-cell survival and differentiation $(47,48)$. It was also found to have a positive association with the mRNA expression level of BCL2 and to prevent cell apoptosis $(49,50)$. Notably, FOXP1 was found to act as a transcription factor to activate the transcription of lncRNAs, thereby increasing their expression $(30,51)$. Based on the results of the present study, FOXP1 was shown to combine with miR-589-5p, and its mRNA expression level was inversely correlated with miR-589-5p and directly correlated with TTN-AS1 mRNA expression level. Furthermore, FOXP1 was confirmed to interact with the TTN-AS1 promoter and upregulate TTN-AS1 mRNA expression level.

To the best of our knowledge, the present study was the first to examine the function of TTN-AS1 in PC cell lines and investigate the underlying mechanism. The results demonstrated that FOXP1-mediated upregulation of TTN-AS1, promoted PC progression by sponging miR-589-5p and targeting FOXP1, uncovering the presence of a TTN-AS1/miR-589-5p/FOXP1 feedback loop in PC cell lines. These findings may prove to be of value in the research of PC treatment. However, the lack of in vivo nude mouse tumor formation experiments constitutes a limitation of the present study. Therefore, further in vivo experiments will be conducted to verify the regulatory role of the TTN-AS1/miR-589-5p/FOXP1 feedback loop in PC.

\section{Acknowledgements}

Not applicable.

\section{Funding}

No funding was received.

\section{Availability of data and materials}

The datasets used and/or analyzed during the current study are available from the corresponding author upon reasonable request.

\section{Authors' contributions}

JZ and JY designed the present study. JZ, FW and JY performed the experiments, analyzed the data and prepared the figures. JZ and JY drafted the initial manuscript. JZ and JY confirmed the authenticity of all the raw data. All authors have read and approved the final manuscript.

\section{Ethics approval and consent to participate}

The present study was approved by the Ethics Committee of Liyang People's Hospital (Liyang, China) and written informed consent was provided by all patients prior to the study start.

\section{Patient consent for publication}

Not applicable.

\section{Competing interests}

The authors declare that they have no competing interests.

\section{References}

1. Abel EV and Simeone DM: Biology and clinical applications of pancreatic cancer stem cells. Gastroenterology 144: 1241-1248, 2013.

2. McGuire S: World cancer report 2014. Geneva, Switzerland: World health organization, international agency for research on cancer, WHO press, 2015. Adv Nutr 7: 418-419, 2016.

3. Ansari D, Tingstedt B, Andersson B, Holmquist F, Sturesson C, Williamsson C, Sasor A, Borg D, Bauden M and Andersson R: Pancreatic cancer: Yesterday, today and tomorrow. Future Oncol 12: 1929-1946, 2016.

4. Shin SJ, Park H, Sung YN, Yoo C, Hwang DW, Park JH, Kim KP, Lee SS, Ryoo BY, Seo DW, et al: Prognosis of pancreatic cancer patients with synchronous or metachronous malignancies from other organs is better than those with pancreatic cancer only. Cancer Res Treat 50: 1175-1185, 2018.

5. Han Q, Li J, Xiong J and Song Z: Long noncoding RNA LINC00514 accelerates pancreatic cancer progression by acting as a ceRNA of miR-28-5p to upregulate Raplb expression. J Exp Clin Cancer Res 39: 151, 2020.

6. Halbrook CJ and Lyssiotis CA: Employing metabolism to improve the diagnosis and treatment of pancreatic cancer. Cancer Cell 31: 5-19, 2017

7. Beermann J, Piccoli MT, Viereck J and Thum T: Non-coding RNAs in development and disease: Background, mechanisms, and therapeutic approaches. Physiol Rev 96: 1297-1325, 2016.

8. Wei JW, Huang K, Yang C and Kang CS: Non-coding RNAs as regulators in epigenetics (Review). Oncol Rep 37: 3-9, 2017.

9. Dykes IM and Emanueli C: Transcriptional and post-transcriptional gene regulation by long non-coding RNA. Genomics Proteomics Bioinformatics 15: 177-186, 2017.

10. Tsai MC, Manor O, Wan Y, Mosammaparast N, Wang JK, Lan F, Shi Y, Segal E and Chang HY: Long noncoding RNA as modular scaffold of histone modification complexes. Science 329: 689-693, 2010. 
11. Cao Y, Xiong JB, Zhang GY, Liu Y, Jie ZG and Li RZ: Long noncoding RNA UCA1 regulates PRL-3 expression by sponging microRNA-495 to promote the progression of gastric cancer. Mol Ther Nucleic Acids 19: 853-864, 2020

12. Luan Y, Li X, Luan Y, Zhao R, Li Y, Liu L, Hao Y, Vladimir BO and Jia L: Circulating lncRNA UCA1 promotes malignancy of colorectal cancer via the miR-143/MYO6 axis. Mol Ther Nucleic Acids 19: 790-803, 2020.

13. Malik SS, Zia A, Mubarik S, Masood N, Rashid S, Sherrard A, Khan MB and Khadim MT: Correlation of MLH1 polymorphisms, survival statistics, in silico assessment and gene downregulation with clinical outcomes among breast cancer cases. Mol Biol Rep 47: 683-692, 2020.

14. Salmena L, Poliseno L, Tay Y, Kats L and Pandolfi PP: A ceRNA hypothesis: The rosetta stone of a hidden RNA language? Cell 146: 353-358, 2011.

15. Pan S, Shen M, Zhou M, Shi X, He R, Yin T, Wang M, Guo X and Qin R: Long noncoding RNA LINC01111 suppresses pancreatic cancer aggressiveness by regulating DUSP1 expression via microRNA-3924. Cell Death Dis 10: 883, 2019.

16. Lei S, He Z, Chen T, Guo X, Zeng Z, Shen Y and Jiang J: Long noncoding RNA 00976 promotes pancreatic cancer progression through OTUD7B by sponging miR-137 involving EGFR/MAPK pathway. J Exp Clin Cancer Res 38: 470, 2019.

17. Sun Y, Zhu Q, Yang W, Shan Y, Yu Z, Zhang Q and Wu H: LncRNA H19/miR-194/PFTK1 axis modulates the cell proliferation and migration of pancreatic cancer. J Cell Biochem 120 3874-3886, 2019

18. Dong MM, Peng SJ, Yuan YN and Luo HP: LncRNA TTN-AS1 contributes to gastric cancer progression by acting as a competing endogenous RNA of miR-376b-3p. Neoplasma 66: 564-575, 2019.

19. Cui Z, Luo Z, Lin Z, Shi L, Hong Y and Yan C: Long non-coding RNA TTN-AS1 facilitates tumorigenesis of papillary thyroid cancer through modulating the miR-153-3p/ZNRF2 axis. J Gene Med 21: e3083, 2019.

20. Chen P, Wang R, Yue Q and Hao M: Long non-coding RNA TTN-AS1 promotes cell growth and metastasis in cervical cancer via miR-573/E2F3. Biochem Biophys Res Commun 503: 2956-2962, 2018.

21. Zhou Y, Huang Y, Dai T, Hua Z, Xu J, Lin Y, Han L, Yue X, Ho L, Lu J and Ai X: LncRNA TTN-AS1 intensifies sorafenib resistance in hepatocellular carcinoma by sponging miR-16-5p and upregulation of cyclin E1. Biomed Pharmacother 133: 111030,2021

22. Jia Y, Duan Y, Liu T, Wang X, Lv W, Wang M, Wang J and Liu L: LncRNA TTN-AS1 promotes migration, invasion, and epithelial mesenchymal transition of lung adenocarcinoma via sponging miR-142-5p to regulate CDK5. Cell Death Dis 10: 573, 2019.

23. Fu SW, Zhang Y, Li S, Shi ZY, Zhao J and He QL: LncRNA TTN-AS1 promotes the progression of oral squamous cell carcinoma via miR-411-3p/NFAT5 axis. Cancer Cell Int 20: 415, 2020.

24. Feng H, Wang Q, Xiao W, Zhang B, Jin Y and Lu H: LncRNA TTN-AS1 regulates miR-524-5p and RRM2 to promote breast cancer progression. Onco Targets Ther 13: 4799-4811, 2020.

25. Livak KJ and Schmittgen TD: Analysis of relative gene expression data using real-time quantitative PCR and the 2(-Delta Delta $\mathrm{C}(\mathrm{T}))$ method. Methods 25: 402-408, 2001.

26. Wang W, Lou W, Ding B, Yang B, Lu H, Kong Q and Fan W: A novel mRNA-miRNA-lncRNA competing endogenous RNA triple sub-network associated with prognosis of pancreatic cancer. Aging (Albany NY) 11: 2610-2627, 2019.

27. Chan JJ and Tay Y: Noncoding RNA:RNA regulatory networks in cancer. Int J Mol Sci 19: 1310, 2018.

28. Lai XN, Li J, Tang LB, Chen WT, Zhang L and Xiong LX: MiRNAs and LncRNAs: Dual roles in TGF- $\beta$ signaling-regulated metastasis in lung cancer. Int J Mol Sci 21: 1193, 2020.

29. Wang C, Tan C, Wen Y, Zhang D, Li G, Chang L, Su J and Wang X: FOXP1-induced lncRNA CLRN1-AS1 acts as a tumor suppressor in pituitary prolactinoma by repressing the autophagy via inactivating Wnt $/ \beta$-catenin signaling pathway. Cell Death Dis 10: 499, 2019.

30. Gong T, Li Y, Feng L, Fang MZ, Dai G, Huang X, Yang Y and Liu S: CASC21, a FOXP1 induced long non-coding RNA, promotes colorectal cancer growth by regulating CDK6. Aging (Albany NY) 12: 12086-12106, 2020.

31. Yan J, Jia Y, Chen H, Chen W and Zhou X: Long non-coding RNA PXN-AS1 suppresses pancreatic cancer progression by acting as a competing endogenous RNA of miR-3064 to upregulate PIP4K2B expression. J Exp Clin Cancer Res 38: $390,2019$.
32. Yao GW,Bai JR and Zhang DP: P21 activated kinase 2 promotes pancreatic cancer growth and metastasis. Oncol Lett 17: 3709-3718, 2019.

33. Dugimont T, Curgy JJ, Wernert N, Delobelle A, Raes MB, Joubel A, Stehelin D and Coll J: The H19 gene is expressed within both epithelial and stromal components of human invasive adenocarcinomas. Biol Cell 85: 117-124, 1995.

34. Verkerk AJ, Ariel I, Dekker MC, Schneider T, van Gurp RJ, de Groot N, Gillis AJ, Oosterhuis JW, Hochberg AA and Looijenga LH: Unique expression patterns of H19 in human testicular cancers of different etiology. Oncogene 14: 95-107, 1997.

35. Ji P, Diederichs S, Wang W, Böing S, Metzger R, Schneider PM, Tidow N, Brandt B, Buerger H, Bulk E, et al: MALAT-1, a novel noncoding RNA, and thymosin beta4 predict metastasis and survival in early-stage non-small cell lung cancer. Oncogene 22: 8031-8041, 2003.

36. Tahira AC, Kubrusly MS, Faria MF, Dazzani B, Fonseca RS Maracaja-Coutinho V, Verjovski-Almeida S, Machado MCC and Reis EM: Long noncoding intronic RNAs are differentially expressed in primary and metastatic pancreatic cancer. Mol Cancer 10: 141, 2011.

37. Kim K, Jutooru I, Chadalapaka G, Johnson G, Frank J, Burghardt R, Kim S and Safe S: HOTAIR is a negative prognostic factor and exhibits pro-oncogenic activity in pancreatic cancer. Oncogene 32: 1616-1625, 2013.

38. Guttman M, Amit I, Garber M, French C, Lin MF, Feldser D, Huarte M, Zuk O, Carey BW, Cassady JP, et al: Chromatin signature reveals over a thousand highly conserved large non-coding RNAs in mammals. Nature 458: 223-227, 2009.

39. Vasudevan S, Tong Y and Steitz JA: Switching from repression to activation: MicroRNAs can up-regulate translation. Science 318: 1931-1934, 2007.

40. Yu D, Han GH, Zhao X, Liu X, Xue K, Wang D and Xu CB: MicroRNA-129-5p suppresses nasopharyngeal carcinoma lymphangiogenesis and lymph node metastasis by targeting ZIC2. Cell Oncol (Dordr) 43: 249-261, 2020.

41. Fellenberg J, Lehner B, Saehr H, Schenker A and Kunz P: Tumor suppressor function of miR-127-3p and miR-376a-3p in osteosarcoma cells. Cancers (Basel) 11: 2019, 2019.

42. Guo S, Fesler A, Huang W, Wang Y, Yang J, Wang X, Zheng Y, Hwang GR, Wang $\mathrm{H}$ and Ju J: Functional significance and therapeutic potential of miR-15a mimic in pancreatic ductal adenocarcinoma. Mol Ther Nucleic Acids 19: 228-239, 2020.

43. Georgikou C, Yin L, Gladkich J, Xiao X, Sticht C, de la Torre C, Gretz N, Gross W, Schäfer M, Karakhanova S and Herr I: Inhibition of miR30a-3p by sulforaphane enhances gap junction intercellular communication in pancreatic cancer. Cancer Lett 469: 238-245, 2020.

44. Cesana M, Cacchiarelli D, Legnini I, Santini T, Sthandier O, Chinappi M, Tramontano A and Bozzoni I: A long noncoding RNA controls muscle differentiation by functioning as a competing endogenous RNA. Cell 147: 358-369, 2011.

45. Wang Y, Dong L and Liu Y: Targeting thyroid receptor interacting protein 6 by MicroRNA-589-5p inhibits cell proliferation, migration, and invasion in endometrial carcinoma. Cancer Biother Radiopharm 34: 529-536, 2019.

46. Zhu Q, Luo Z, Lu G, Gui F, Wu J, Li F and Ni Y: LncRNA FABP5P3/miR-589-5p/ZMYND19 axis contributes to hepatocellular carcinoma cell proliferation, migration and invasion. Biochem Biophys Res Commun 498: 551-558, 2018.

47. Hu H, Wang B, Borde M, Nardone J, Maika S, Allred L, Tucker PW and Rao A: Foxp1 is an essential transcriptional regulator of B cell development. Nat Immunol 7: 819-826, 2006.

48. Craig VJ, Cogliatti SB, Imig J, Renner C, Neuenschwander S, Rehrauer H, Schlapbach R, Dirnhofer S, Tzankov A and Müller A: Myc-mediated repression of microRNA-34a promotes high-grade transformation of B-cell lymphoma by dysregulation of FoxP1. Blood 117: 6227-6236, 2011.

49. Yu B, Zhou X, Li B, Xiao X, Yan S and Shi D: FOXP1 expression and its clinicopathologic significance in nodal and extranodal diffuse large B-cell lymphoma. Ann Hematol 90: 701-708, 2011.

50. Sagaert X, de Paepe P, Libbrecht L, Vanhentenrijk V, Verhoef G, Thomas J, Wlodarska I and De Wolf-Peeters C: Forkhead box protein P1 expression in mucosa-associated lymphoid tissue lymphomas predicts poor prognosis and transformation to diffuse large B-cell lymphoma. J Clin Oncol 24: 2490-2497, 2006.

51. Wu M, Huang Y, Chen T, Wang W, Yang S, Ye Z and Xi X: LncRNA MEG3 inhibits the progression of prostate cancer by modulating miR-9-5p/QKI-5 axis. J Cell Mol Med 23: 29-38, 2019.

This work is licensed under a Creative Commons Attribution-NonCommercial-NoDerivatives 4.0 International (CC BY-NC-ND 4.0) License. 